Claremont Colleges

Scholarship@ Claremont

All HMC Faculty Publications and Research

HMC Faculty Scholarship

$12-22-1998$

\title{
An Ab Initio Study of the Mono- and Difluorides of Krypton
}

Gerald J. Hoffman

College of New Jersey

Laura A. Swafford '97

Pomona College

Robert J. Cave

Harvey Mudd College

\section{Recommended Citation}

An ab initio study of the mono- and difluorides of krypton. Gerald J. Hoffman, Laura A. Swafford, and Robert J. Cave, J. Chem. Phys. 109, 10701 (1998), DOI:10.1063/1.477768

This Article is brought to you for free and open access by the HMC Faculty Scholarship at Scholarship @ Claremont. It has been accepted for inclusion in All HMC Faculty Publications and Research by an authorized administrator of Scholarship @ Claremont. For more information, please contact scholarship@cuc.claremont.edu. 


\title{
An $a b$ initio study of the mono- and difluorides of krypton
}

\author{
Gerald J. Hoffman a) \\ Department of Chemistry, The College of New Jersey, P.O. Box 7718, Ewing, New Jersey 08628-0718 \\ Laura A. Swafford \\ Department of Chemistry, Pomona College, 645 N. College Avenue, Claremont, California 91711
}

Robert J. Cave ${ }^{\text {b) }}$

Department of Chemistry, Harvey Mudd College, Claremont, California 91711

(Received 2 July 1998; accepted 16 September 1998)

\begin{abstract}
Results from $a b$ initio calculations at the $\operatorname{CCSD}(\mathrm{T})$ level of theory are presented for krypton monofluoride $(\mathrm{KrF})$, krypton monofluoride cation $\left(\mathrm{KrF}^{+}\right)$, linear, ground-state krypton difluoride $\left(\mathrm{KrF}_{2}\right)$, the triplet state of krypton difluoride, and the krypton-fluorine van der Waals complex $\left(\mathrm{Kr}-\mathrm{F}_{2}\right)$. These are the first calculations demonstrating that $\mathrm{KrF}$ is a bound molecule, in agreement with experimental observation. When corrected for basis-set superposition error, the calculated potential displays quantitative agreement with the attractive wall of the experimentally measured potential curve. Results are also presented for $\mathrm{KrF}^{+}$and linear $\mathrm{KrF}_{2}$ which yield accurate values for their dissociation energies. The triplet state of $\mathrm{KrF}_{2}$ is found to have a minimum energy below that of separated atoms, and its structure is bent, with a small $\mathrm{F}-\mathrm{Kr}-\mathrm{F}$ bond angle $(71 \mathrm{deg})$. The van der Waals complex, $\mathrm{Kr}-\mathrm{F}_{2}$, appears to consist of an unperturbed $\mathrm{F}_{2}$ molecule attached to a krypton atom in the expected T-shaped structure. () 1998 American Institute of Physics.

[S0021-9606(98)30448-1]
\end{abstract}

\section{INTRODUCTION}

Since their discovery, compounds containing noble-gas atoms have presented a conceptual challenge to chemistry because they violate conventional rules of bonding. Krypton difluoride was among the first of such compounds to be discovered. ${ }^{1,2}$ Several quantum chemical studies on this molecule have been published; ${ }^{3-6}$ early on, the importance of accounting for electron correlation was emphasized in order to obtain results consistent with experiment. ${ }^{3}$

The noble-gas monohalides are a class of compounds that are even more interesting than the dihalides due to their spectroscopic properties. The excited electronic states, having principally charge-transfer character, are much more strongly bound than the ground states to which they radiatively relax. Noble-gas monohalides are now commonly used as the active media in high-powered ultraviolet gas excimer lasers. Early $a b$ initio calculations predicted dissociative ground electronic states for these molecules; ${ }^{7-11}$ however, crossed molecular-beam studies clearly show bound ground states, ${ }^{12,13}$ though the binding energies are small. Recently published results of high-level calculations on the halides of xenon have yielded ground-state potentials in remarkably good agreement with experimental ones; ${ }^{14}$ these are the first such results to be reported for any of the noble-gas monohalides.

Experiments on fluorides of krypton and xenon in lowtemperature matrices suggest that there is another species which is spectroscopically distinct from either the monofluoride or the well known difluoride. The observed krypton spe-

\footnotetext{
a) Author to whom correspondence should be addressed.

${ }^{b)}$ Camille and Henry Dreyfus Teacher-Scholar.
}

cies has fluorescence and excitation spectra similar to, but still distinguishable from, the clearly identifiable monofluoride, $\mathrm{KrF}^{15}$ The fluorescence and excitation spectra of the analogous xenon species, on the other hand, appear to be entirely different from its corresponding monofluoride, $\mathrm{XeF} ;{ }^{16-18}$ further, this new xenon species displays very interesting relaxation dynamics, ${ }^{18}$ and can be made to lase quite readily. ${ }^{19}$ Hence, it would be useful to understand the nature of this interesting molecule.

Because the fluorescence of these species appears to be from charge-transfer-like states, it has been suggested that these species are the monofluorides of $\mathrm{Kr}$ and $\mathrm{Xe}$ perturbed by a nearby fluorine atom. ${ }^{15,17}$ However, if a fluorine atom is close enough to perturb the monfluoride species significantly, it may be close enough to bond directly to it. Indeed, this species with interesting spectroscopic properties may be a low-lying electronic state of the difluoride which is stable only at temperatures near $0 \mathrm{~K}$. This may be either the triplet state of $\mathrm{KrF}_{2}$ or the van der Waals complex, $\mathrm{Kr}-\mathrm{F}_{2}$, neither of which has clearly been identified experimentally. Either of these species may have excited charge-transfer states in its electronic manifold, which could explain the observed spectroscopy. The objective of this paper is to begin testing the validity of this hypothesis for $\mathrm{KrF}_{2}$ by determining whether these species are stable using ab initio techniques.

$\mathrm{KrF}$ provides an ideal starting point for a study on weakly-bound species. Until now there has been no ab initio calculation showing $\mathrm{KrF}$ to be a bound molecule. Further, a potential curve for the ground state of this molecule based on experimental results ${ }^{20}$ allows assessment of the quality of the calculation. For certain basis sets, coupled-cluster theory calculations including singles, doubles, and noniterative triples 
[CCSD(T)] on KrF, with correction for basis-set superposition error (BSSE), is seen to give quantitative agreement with experiment on the attractive wall of the potential. While this combination of technique and basis sets does not give particularly good agreement with the experimentally reported bond length and dissociation energy, the fact that the technique results in a bound molecule at all suggests it is sufficiently trustworthy to test on other weakly bound species. Additionally, the krypton monofluoride cation, $\mathrm{KrF}^{+}$, and the ground singlet state of $\mathrm{KrF}_{2}$ are studied, yielding results superior to previous calculations. The result of calculations on the $\mathrm{KrF}_{2}$ triplet are presented; the geometry of its energy minimum is bent, with a small $\mathrm{F}-\mathrm{Kr}-\mathrm{F}$ bond angle (71 deg). Finally, the minimum energy geometry of the $\mathrm{Kr}-\mathrm{F}_{2}$ van der Waals complex is presented.

\section{COMPUTATIONAL DETAILS}

All results were obtained using GAUSSIAN $94 .{ }^{21}$ Most calculations were performed on the Cray C90 at the San Diego Supercomputer Center (SDSC); others were performed on a Silicon Graphics Indigo 2 workstation. krypton:

The basis sets chosen for this study are as follows: For

SHA: An all-electron triple-zeta basis set developed by Schafer, Huber, and Ahlrichs. ${ }^{22,23}$

(ii) EPC-1: The averaged relativistic effective core potential (ECP) basis set of Christiansen, Ross, Ermler, and others ${ }^{24}$ having only $4 s$ and $4 p$ valence functions; for these calculations, the valence shells were uncontracted.

Both of these basis sets were augmented by two $d$ (exponents 0.612 and 0.182$)^{25}$ and one $f$ (exponent 0.40$)^{6}$ polarization subshells, and diffuse $s$ and $p$ subshells (exponents 0.0634 and 0.0330 , respectively).

For fluorine:

HUZ: Huzinaga's (73/7) basis set for fluorine ${ }^{25}$ with the outer $s$ and $p$ subshells doubly split augmented with two $d$ polarization subshells (exponents 3.559 and 0.682$)^{25}$ and $s$ and $p$ diffuse subshells (exponents 0.123 and 0.0601 , respectively).

(ii) WMR: A basis set of atomic natural orbitals (ANOs) developed by Widmark, Malmqvist, and Roos ${ }^{23,26}$ which includes all orbitals through principle quantum number $n=5$ except for the $5 g$ subshell; this basis set was used as is, without splitting or augmentation.

The method chosen for calculation was $\operatorname{CCSD}(\mathrm{T}) .{ }^{27} \mathrm{As}$ has been noted elsewhere in the context of $\mathrm{XeF}^{14}$ inclusion of the effect of triples greatly improves the quality of the calculated potential over that of CCSD. Additionally, the calculated energies were usually corrected by subtracting the BSSE calculated using the counterpoise method. ${ }^{28,29}$ While not an exact predictor of BSSE, the counterpoise method ought to give a semiquantitative estimate of its effects, which is necessary to avoid results artificially biased toward dissociation energies that are too large.

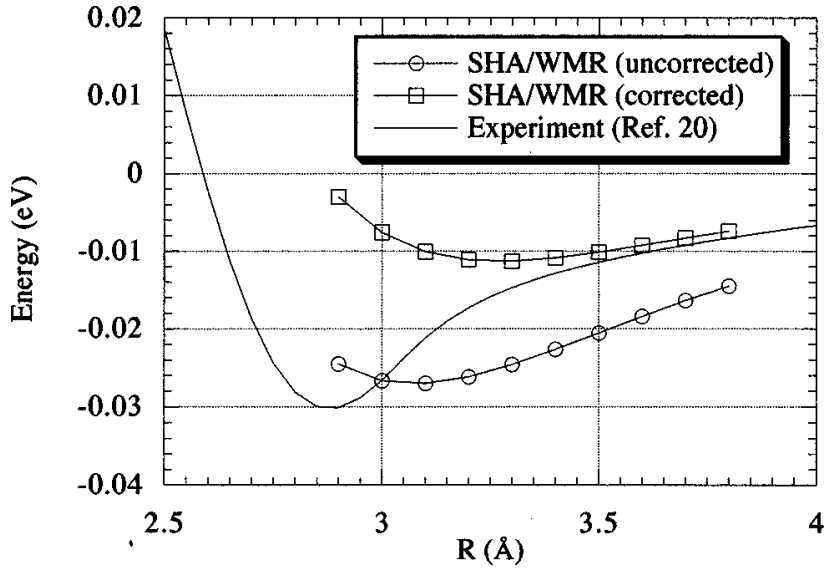

FIG. 1. CCSD(T) potential energy curve of $\mathrm{KrF}$ using the SHA/WMR basisset combination, with and without BSSE correction, compared with experiment. Experimental curve is from Ref. 20.

\section{RESULTS AND DISCUSSION}

\section{A. $\mathrm{KrF}$}

Previous calculations on $\mathrm{KrF}$, performed at the SCF-CI level, did not result in a ground-state potential with a minimum. ${ }^{7,9,10}$ The studies by Dunning and Hay, ${ }^{9-11}$ however, did reveal a great deal of information about the excited charge-transfer states of this and other noble-gas monohalides, much of which is still quite valuable. Until very recently, ${ }^{14}$ there have been no attempts to apply more modern techniques to this general problem. Our objective is to find an $a b$ initio technique capable of producing a groundstate potential for $\mathrm{KrF}$ which is bound. It is hoped that such a technique is sufficiently trustworthy to be predictive with regard to species which have not been definitively identified in experiment, unlike $\mathrm{KrF}$.

Figure 1 shows the calculated potential curves for $\mathrm{KrF}$ using the SHA/WMR basis-set combination, both with and without BSSE correction. The potential curve from experiment ${ }^{20}$ is provided also for comparison. While the uncorrected $a b$ initio potential curve gives a bond length and dissociation energy closer to the experimental values, the points on the uncorrected curve do not lie near the experimental one. On the other hand, the points on the corrected curve in the attractive region agree almost exactly with the experimental curve. This region of the experimental potential is the portion which has been most reliably measured. ${ }^{30}$ The quality of the observed agreement between experiment and calculation in the region where the experimental results are on their firmest footing suggests that the technique and basis sets used are giving realistic and trustworthy results. Note also that correcting for BSSE affects not just the energy, but also the bond length; the minimum in the calculated potential is pushed further out after correction. This reflects the decrease in BSSE as separation between the atoms increases. Because BSSE clearly has a profound effect on the energy of weakly bound molecules, and because the structure of previously unknown and weakly bound molecules are being sought (triplet $\mathrm{KrF}_{2}$ and $\mathrm{Kr}-\mathrm{F}_{2}$ van der Waals complex), subtraction of BSSE from the minimum energy geometry of such species is necessary to make sure they are truly bound. 


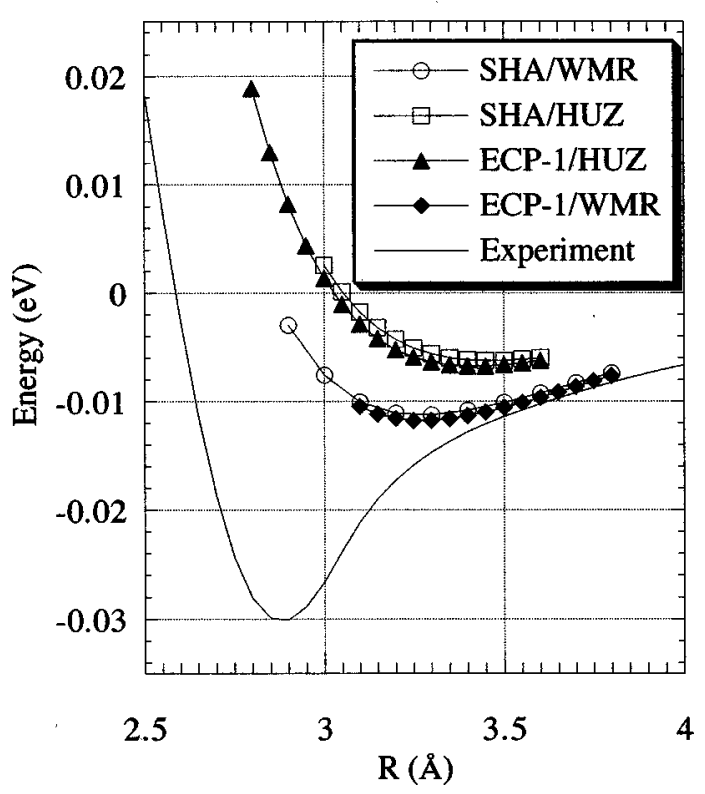

FIG. 2. BSSE-corrected $\operatorname{CCSD}(\mathrm{T})$ potential energy curves for $\mathrm{KrF}$, compared with experiment, using the following basis-set combinations: SHA/ HUZ, ECP-1/HUZ, SHA/WMR, ECP-1/WMR. Experimental curve is from Ref. 20.

Figure 2 displays the $\mathrm{CCSD}(\mathrm{T})$ potential curves of $\mathrm{KrF}$, corrected for BSSE, for four combinations of basis sets. All result in bound potentials, the first calculated for this molecule, though quantitative agreement on the attractive wall apparently requires the use of the WMR basis set for fluorine. Agreement is marginally better for ECP-1/WMR than for SHA/WMR. Use of the ECP-1/basis set is preferred over use of SHA due to the computer time saved by neglecting the core electrons of krypton, but it is interesting nonetheless to note that the nonrelativistic SHA basis set performs almost as well as the relativistic ECP-1 basis set. Table I gives $\operatorname{CCSD}(\mathrm{T})$ bond lengths and dissociation energies of $\mathrm{KrF}$ for the various basis-set combinations, both corrected and uncorrected for BSSE. Note that the dissociation energies are calculated with respect to the energies of the separated atoms $\operatorname{Kr}\left({ }^{1} \mathrm{~S}\right)$ and $\mathrm{F}\left({ }^{2} \mathrm{P}\right)$. (As spin-orbit coupling was not included in any of these calculations, no reference is made to the $j$-states of the separated atoms.) Experimental values are provided for comparison.

Considering the high level of theory at which the calculation is performed, and the care with which it is applied, there is still considerable disagreement between the experi-

TABLE I. CCSD(T) bond lengths and binding energies of $\mathrm{KrF}$ for various basis sets, with and without BSSE correction.

\begin{tabular}{llllll}
\hline \hline \multirow{2}{*}{$\begin{array}{c}\text { Basis set } \\
(\mathrm{Kr} / \mathrm{F})\end{array}$} & \multicolumn{2}{c}{ BSSE corrected } & & \multicolumn{2}{c}{ Uncorrected } \\
\cline { 2 - 3 } \cline { 5 - 6 } & $R_{e}(\AA)$ & $D_{e}(\mathrm{eV})$ & & $R_{e}(\AA)$ & $D_{e}(\mathrm{eV})$ \\
\hline SHA/HUZ & 3.47 & 0.00626 & & 3.26 & 0.01491 \\
ECP-1/HUZ & 3.42 & 0.00678 & & 3.260 & 0.01401 \\
SHA/WMR & 3.27 & 0.01130 & & 3.07 & 0.02703 \\
ECP-1/WMR & 3.27 & 0.01181 & & 3.08 & 0.02478 \\
Experiment & $2.875^{\mathrm{a}}$ & $0.0301^{\mathrm{a}}$ & & & \\
\hline \hline
\end{tabular}

${ }^{\mathrm{a}}$ Reference 20 .
TABLE II. BSSE-corrected CCSD(T) bond lengths and binding energies of $\mathrm{KrF}^{+}$for various basis sets.

\begin{tabular}{llc}
\hline \hline $\begin{array}{l}\text { Basis set } \\
(\mathrm{Kr} / \mathrm{F})\end{array}$ & $R_{e}(\AA)$ & $D_{e}(\mathrm{eV})$ \\
\hline ECP-1/HUZ & 1.77 & 1.70 \\
SHA/WMR & 1.76 & 1.78 \\
ECP-1/WMR & 1.75 & 1.82 \\
Previous & $1.752^{\mathrm{a}}$ & $1.94^{\mathrm{a}}$ \\
calculation & & \\
Experiment & & $D_{0} \geqslant 1.58^{\mathrm{b}}$ \\
\hline \hline
\end{tabular}

${ }^{a}$ Reference 7; this is the result of an SCF-CI calculation, without BSSE correction.

${ }^{\mathrm{b}}$ Reference 33 .

mental and the best calculated potential curves. Schröder et al. ${ }^{14}$ observed similar disagreement in their $\operatorname{CCSD}(\mathrm{T})$ calculations on $\mathrm{XeF}$ (using a relativistic effective core potential basis set for $\mathrm{Xe}$, and an augmented, correlation-consistent basis set for F). They suggested that this reflects a failure of the coupled-cluster technique to accurately reflect the multiconfigurational nature of the wave function. ${ }^{14}$ These workers ${ }^{14}$ then applied the multireference-averaged coupledpair functional (MR-ACPF) technique in order to incorporate some of the charge-transfer states into the ground-state wave function; this resulted in a $28 \%$ increase in the dissociation energy of XeF over $\mathrm{CCSD}(\mathrm{T})$, uncorrected for BSSE. Then, the effects of spin-orbit coupling, quite large for $\mathrm{Xe}^{+}$, were also included in the calculation. ${ }^{14}$ The resulting potential minimum, uncorrected for BSSE, agrees very closely with experimental values for bond length and dissociation energy, the latter improved over the CCSD(T) value by about $43 \% .{ }^{14}$

It is expected that a treatment which takes into account the fractional charge-transfer character of the ground state of $\mathrm{KrF}$, as well as the spin-orbit coupling associated with the partially positively charged krypton atom, will increase the dissociation energy and perhaps reduce the disagreement between calculated results and experiment. Our calculated dipole moment $(0.014 D$, with fluorine on the negative end) is surely too small, indicating a need to include the mixing of covalent and charge-transfer states into the calculation. Because such mixing is included in the calculations of Dunning and Hay, ${ }^{9-11}$ their dipole moment for the ground state of $\mathrm{KrF}$ $(0.25 \mathrm{D} \text { at } 3.25 \AA)^{10}$ is certainly more accurate than ours. Using this value for the dipole moment and the spin-orbit coupling of the $\mathrm{Kr}^{+}\left({ }^{2} \mathrm{P}\right)$ ion $(0.67 \mathrm{eV}),{ }^{31}$ a crude estimate is obtained for the spin-orbit coupling in the ground state of $\mathrm{KrF}$ on the order of $\sim 0.01 \mathrm{eV} .^{32}$ The fact that this estimate is of the same order as our calculated dissociation energy suggests a calculation including both mixing of covalent and charge-transfer states and a careful treatment of spin-orbit effects could bring theoretical results significantly closer to experiment in the region of the minimum. We intend to perform such a calculation in the near future by application of a multireference technique.

\section{B. $\mathrm{KrF}^{+}$}

Table II gives the BSSE-corrected $\operatorname{CCSD}(\mathrm{T})$ bond lengths and dissociation energies of $\mathrm{KrF}^{+}$for various basisset combinations, as well as the literature values for these 
TABLE III. BSSE-corrected CCSD(T) bond lengths and binding energies of $\mathrm{KrF}_{2}$ for various basis sets.

\begin{tabular}{llc}
\hline \hline $\begin{array}{c}\text { Basis set } \\
(\mathrm{Kr} / \mathrm{F})\end{array}$ & $R_{e}(\AA)$ & $D_{e}(\mathrm{eV})$ \\
\hline $\mathrm{SHA} / \mathrm{HUZ}$ & 1.92 & 0.470 \\
$\mathrm{ECP}-1 / \mathrm{HUZ}$ & 1.91 & 0.524 \\
$\mathrm{SHA} / \mathrm{WMR}$ & 1.90 & 0.575 \\
$\mathrm{ECP}-1 / \mathrm{WMR}$ & 1.89 & 0.771 \\
Previous & $1.907^{\mathrm{a}}$ & $0.39^{\mathrm{a}}$ \\
$\quad$ calculation & $1.919^{\mathrm{b}}$ & \\
Experiment & $1.8769^{\mathrm{b}}$ & $1.01^{\mathrm{c}}$ \\
\hline \hline
\end{tabular}

${ }^{a}$ Reference 3; this is the result of an SCF-CI calculation, without BSSE correction.

${ }^{\mathrm{b}}$ Reference 6 . The calculated bond length quoted here from Ref. 6 is the result of a $\operatorname{CCSD}(\mathrm{T})$ calculation using a different basis set, without BSSE correction; the authors point out that their CCSD bond length, $1.8876 \AA$, is closer to the experimental bond length than that of $\operatorname{CCSD}(\mathrm{T})$.

${ }^{\mathrm{c}}$ Reference 34.

quantities. The separated atom limit to which the dissociation energies are referenced corresponds to a ground-state krypton cation $\left[\mathrm{Kr}^{+}\left({ }^{2} \mathrm{P}\right)\right]$ and a fluorine atom in its ground state $\left[\mathrm{F}\left({ }^{2} \mathrm{P}\right)\right]$. The dissociation energy from previous calculations originates from SCF-CI calculations, without accounting for BSSE. $^{7}$ The results presented here are of significantly higher quality, and thus may supplant the currently accepted value until a more definitive experimental measurement is made on this species. As such, the largest BSSE-corrected dissociation energy calculated in this work, $1.82 \mathrm{eV}$ (using ECP-1/ WMR), may be taken as a more accurate estimate of the dissociation energy for this ion.

\section{Singlet $\mathrm{KrF}_{2}$ (ground state)}

Table III shows the BSSE-corrected bond lengths and dissociation energies for the $\mathrm{KrF}_{2}$ singlet ground state, as well as experimental measurements, and the computational results of others for comparison. The dissociation energies are referenced to a separated-atom limit consisting of a ground-state krypton atom $\left[\operatorname{Kr}\left({ }^{1} \mathrm{~S}\right)\right]$ and two ground-state fluorine atoms $\left[\mathrm{F}\left({ }^{2} \mathrm{P}\right)\right]$. Note that the results presented here are the first to account for BSSE in this molecule. Further, there is only one previously published calculation for the dissociation energy of $\mathrm{KrF}_{2} \cdot{ }^{3}$ Bond lengths are comparable to those previously calculated, and the dissociation energies are a substantial fraction of the experimentally measured value.

$\mathrm{KrF}_{2}$ and the other noble-gas difluorides serve as examples of nonadditivity of bond energies. Assuming the bond energy of a single $\mathrm{Kr}-\mathrm{F}$ bond in $\mathrm{KrF}_{2}$ is just half the total dissociation energy of the molecule, this bond energy $(0.505 \mathrm{eV})^{34,35}$ is more than 15 times larger than the dissociation energy of $\mathrm{KrF}(0.0301 \mathrm{eV}) .^{20} \mathrm{~A}$ similar disparity is observed when considering the $\mathrm{Kr}-\mathrm{F}$ bond lengths in $\mathrm{KrF}$ and $\mathrm{KrF}_{2}$. A simple way to understand this disparity is to consider a model for bonding in $\mathrm{KrF}_{2}$ which applies the concept of resonance. ${ }^{36}$ The familiar Lewis structure for $\mathrm{KrF}_{2}$ can be redrawn in terms of two resonance structures:

$$
(\mathrm{F}-\mathrm{Kr})^{+} \mathrm{F}^{-} \leftrightarrow \mathrm{F}^{-}(\mathrm{Kr}-\mathrm{F})^{+} .
$$

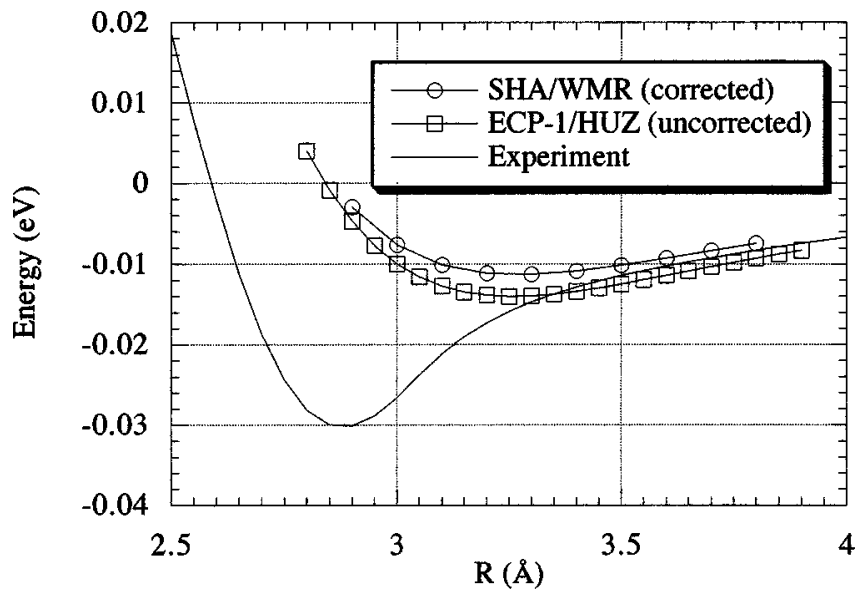

FIG. 3. Uncorrected $\mathrm{CCSD}(\mathrm{T})$ potential energy curve for $\mathrm{KrF}$ using the ECP-1/HUZ basis-set combination, compared with experiment and the BSSE-corrected CCSD(T) potential energy curve using SHA/WMR. Experimental curve is from Ref. 20.

In a single resonance structure, the $\mathrm{Kr}$ and $\mathrm{F}$ atoms in the $\mathrm{KrF}^{+}$cation are held together by a covalent bond, while the $\mathrm{F}^{-}$is bound to $\mathrm{KrF}^{+}$by Coulomb attraction. The $\mathrm{Kr}-\mathrm{F}$ bond length one would expect from this model would be somewhere between that for $\mathrm{KrF}^{+}$and, approximately, that for $\mathrm{Kr}^{+} \mathrm{F}^{-}$, one of the excited charge-transfer states of $\mathrm{KrF}$. The $\mathrm{KrF}^{+}$bond length calculated above is $1.75 \AA$, and the most recent estimate of the equilibrium separation for the $B(1 / 2)$ charge transfer state of $\mathrm{KrF}$, based on spectroscopic data, is $2.335 \AA \AA^{30}$ The experimentally observed $\mathrm{Kr}-\mathrm{F}$ bond length in $\mathrm{KrF}_{2}, 1.8769 \AA \AA^{6}$, falls between these two values, as this model predicts. Further, the Mullikan atomic charges calculated using the ECP-1/WMR basis-set combination are +0.957 for krypton and -0.478 for fluorine, close to what would be expected according to the resonance structures.

\section{Triplet $\mathrm{KrF}_{2}$}

In the determination of the $\mathrm{KrF}_{2}$ triplet state structure, CPU time became a limiting factor with regard to how the calculations were performed. Even with the smallest basisset combination, ECP-1/HUZ, computation of a single-point energy required more than three hours on the Cray C90; any of the larger basis sets would use still more ungainly amounts of CPU time. Fortunately, a comparison of results from the $\mathrm{KrF}$ calculations shows that this particular basis-set combination, when left uncorrected for BSSE, coincides reasonably closely with the attractive wall of the experimental potential. This is shown in Fig. 3, where this uncorrected $\mathrm{KrF}$ potential is compared with both experiment and with the BSSE-corrected SHA/WMR potential. It appears that neglect of BSSE nearly cancels the error associated with using a less complete fluorine basis set. Because BSSE decreases with increasing bond length, these errors may not cancel at internuclear distances greater than those shown in Fig. 3. However, as will be shown, the minimum triplet structure has a $\mathrm{Kr}-\mathrm{F}$ bond length not unlike that calculated for $\mathrm{KrF}$, and this implies that the most important region for the triplet is one where such cancellation is nearly exact. For this reason, and 
TABLE IV. Uncorrected CCSD(T) structures and energies for $\mathrm{KrF}_{2}$ triplet and $\mathrm{Kr}-\mathrm{F}_{2}$ van der Waals complex.

\begin{tabular}{lcccc}
\hline \hline & $\begin{array}{c}\mathrm{Kr}-\mathrm{F} \\
\text { Bond length } \\
(\AA)\end{array}$ & $\begin{array}{c}\mathrm{F}-\mathrm{Kr}-\mathrm{F} \\
\text { Bond angle }\end{array}$ & $\begin{array}{c}\mathrm{F}-\mathrm{F} \\
\text { Separation } \\
(\AA)\end{array}$ & $\begin{array}{c}\text { Binding } \\
\text { energy }^{\mathrm{a}} \\
(\mathrm{eV})\end{array}$ \\
\hline Triplet $\mathrm{KrF}_{2}$ & 3.269 & $71 \mathrm{deg}$ & 3.797 & 0.02807 \\
$\mathrm{Kr}-\mathrm{F}_{2}$ van der & 3.668 & $22.2 \mathrm{deg}$ & 1.442 & 1.3968 \\
Waals complex & & & & \\
\hline \hline
\end{tabular}

${ }^{\text {a }}$ These binding energies are referenced to the energy of the separated ground-state atoms, $\operatorname{Kr}\left({ }^{1} \mathrm{~S}\right)$ and two $\mathrm{F}\left({ }^{2} \mathrm{P}\right)$.

in the interest of saving CPU time, the ECP-1/HUZ basis-set combination without BSSE correction was used to determine the $\mathrm{KrF}_{2}$ triplet-state structure. However, a BSSE calculation was performed at the minimum energy configuration in order to ensure that the corrected binding energy of the molecule was still sufficient to hold all of the atoms together.

The resulting structure is unexpected; results are summarized in Table IV. The $\mathrm{F}-\mathrm{Kr}-\mathrm{F}$ bond angle is quite small, at $71 \mathrm{deg}$, and the $\mathrm{Kr}-\mathrm{F}$ bond lengths are $3.269 \AA$, on the order of the (uncorrected) calculated bond length of $\mathrm{KrF}$ using this same basis-set combination (3.260 $\mathrm{A})$. The F-F separation in this structure is $3.797 \AA$. The uncorrected binding energy of the triplet at the minimum is $0.02806 \mathrm{eV}$; subtracting the BSSE for this geometry gives an energy $0.00901 \mathrm{eV}$ below that of separated ground-state atoms. These binding energies are referenced to the energies of the separated atoms, one $\operatorname{Kr}\left({ }^{1} \mathrm{~S}\right)$ atom and two $\mathrm{F}\left({ }^{2} \mathrm{P}\right)$ atoms. Note that the latter triplet binding energy is not the binding energy of the BSSEcorrected minimum; as stated earlier, correcting for BSSE changes the geometry of the minimum. Such a study, were it to be performed, would reveal a slightly larger binding energy and somewhat longer $\mathrm{Kr}-\mathrm{F}$ bond lengths. However, note that the corrected energy of the uncorrected minimum is significantly larger that the BSSE-corrected dissociation energy of $\mathrm{KrF}$ using the same basis sets. This implies that the energy of the triplet minimum is lower than that of separated $\mathrm{KrF}$ and $\mathrm{F}$; hence, the triplet state of $\mathrm{KrF}_{2}$ is truly bound. Note also, given what was learned from the study of $\mathrm{KrF}$, that the actual $\mathrm{Kr}-\mathrm{F}$ bond lengths are expected to be shorter, and the total binding energy of the molecule is expected to be greater.

The structure of this molecule is sufficiently unusual to need some attempt at interpretation. The two fluorines, though not separated by a proper bond length, are nonetheless close enough to interact. Interestingly, almost all of the spin density resides on the fluorine atoms, and the dipole moment of the triplet is quite small $(0.0723 \mathrm{D})$. It is possible that the krypton is serving to stabilize the lowest triplet state of $\mathrm{F}_{2}$. No experimental evidence exists suggesting that the lowest triplet of $\mathrm{F}_{2}$ is bound, and $\operatorname{CCSD}(\mathrm{T})$ calculations on this state using the HUZ basis set failed to find a minimum in the diatomic potential out to a separation of $5.50 \AA$. Hence, the evidence supports such an interpretation.

On the other hand, it is possible that, in the actual triplet $\mathrm{KrF}_{2}$ species, an electronic configuration corresponding to the krypton atom in its lowest triplet state interacting with singlet $F_{2}$ contributes significantly. In such a case, the mul- ticonfigurational character of the wave function would be critical to its ground-state structure. Application of multireference techniques to this problem will be applied in the near future to investigate this possibility.

\section{E. $\mathrm{Kr}-\mathrm{F}_{\mathbf{2}}$ van der Waals complex}

As in the case of triplet $\mathrm{KrF}_{2}$, the ECP-1/HUZ basis-set combination was used to study the $\mathrm{Kr}-\mathrm{F}_{2}$ van der Waals complex. Results are summarized in Table IV. The structure corresponding to the minimum in energy, uncorrected for BSSE, is the expected T-shaped complex, where the distance between the two fluorines is $1.442 \AA$, and the distance from the krypton atom to the midpoint between the two fluorines is $3.600 \AA$. The $\mathrm{Kr}-\mathrm{F}$ bond length for this complex is 3.668 $\AA$, and the $\mathrm{F}-\mathrm{Kr}-\mathrm{F}$ bond angle is $22.2 \mathrm{deg}$. The total uncorrected binding energy of the van der Waals complex is calculated to be $1.3968 \mathrm{eV}$. The reference for this energy is, as in all other cases presented here, the energy of the separated atoms in their ground states, one $\operatorname{Kr}\left({ }^{1} \mathrm{~S}\right)$ atom and two $\mathrm{F}\left({ }^{2} \mathrm{P}\right)$ atoms (as opposed to $\mathrm{Kr}$ and $\mathrm{F}_{2}$ ).

The F-F bond length calculated above $(1.442 \AA)$ is identical to the uncorrected $\operatorname{CCSD}(\mathrm{T})$ bond length for the ground state of $F_{2}$ calculated using this basis set (HUZ). From this, we can deduce that the bonding in $F_{2}$ is not greatly affected by the presence of the krypton. The uncorrected $\operatorname{CCSD}(\mathrm{T})$ dissociation energy for $\mathrm{F}_{2}$ resulting from this calculation is $1.3817 \mathrm{eV}$. (Experimental values for $\mathrm{F}_{2}: R_{e}=1.4193 \AA, D_{e}=1.66 \mathrm{eV}$. $)^{37}$ Subtracting the $\operatorname{CCSD}(\mathrm{T})$ dissociation energy of $\mathrm{F}_{2}$ from that of the van der Waals complex yields the uncorrected binding energy of $\mathrm{F}_{2}$ to $\mathrm{Kr}, 0.0151 \mathrm{eV}$; correcting for BSSE between $\mathrm{F}_{2}$ and $\mathrm{Kr}$ at this geometry results in a binding energy of $0.0058 \mathrm{eV}$.

In comparing the results of the calculations on the van der Waals complex to those on the triplet state, it is clear that the singlet potential surface lies at a lower energy than the triplet surface at all points. This is mainly due to the magnitude of the dissociation energy of $F_{2}$ in its ground state. At the geometry of the triplet state, a singlet calculation gives a total uncorrected binding energy of $1.2395 \mathrm{eV}$, which is a total of $0.1422 \mathrm{eV}$ above the uncorrected $\mathrm{F}_{2}-\mathrm{Kr}$ binding energy of the van der Waals complex. Thus, singlet $\mathrm{KrF}_{2}$ in this particular configuration would likely dissociate to $\mathrm{Kr}$ and $F_{2}$. The relative total energies of the singlet and triplet potentials, however, imply that the triplet may readily cross to the singlet surface, particularly in the presence of the highly charged krypton nucleus, with its significant spinorbit coupling.

\section{CONCLUSION}

Results of ab initio calculations on $\mathrm{KrF}, \mathrm{KrF}^{+}$, groundstate linear $\mathrm{KrF}_{2}$, triplet $\mathrm{KrF}_{2}$, and the $\mathrm{Kr}-\mathrm{F}_{2}$ van der Waals complex have been presented. Among these are the first calculations showing $\mathrm{KrF}$ to be a bound molecule, in agreement with experiment. The results for $\mathrm{KrF}^{+}$and linear $\mathrm{KrF}_{2}$ bond length agree with previous calculation, but the BSSEcorrected dissociation energies presented here are of a higher quality. The minimum in the triplet-state potential surface corresponds to a bent structure for the molecule, with a very 
small $\mathrm{F}-\mathrm{Kr}-\mathrm{F}$ bond angle (71 deg). The van der Waals complex appears to correspond to an essentially unperturbed $F_{2}$ molecule bound to a $\mathrm{Kr}$ atom in the expected $\mathrm{T}$-shaped configuration. Given the expected higher quality of MR-ACPF calculations relative to $\operatorname{CCSD}(\mathrm{T})$, as demonstrated with $\mathrm{XeF},{ }^{14}$ it is likely that further work on the triplet $\mathrm{KrF}_{2}$ species is required using multireference-based correlation methods.

The fact that the triplet-state potential surface is higher in energy than that of the singlet surface suggests, with regard to the hypothesis stated at the beginning of this paper, that the van der Waals complex is the most likely candidate of the two suggested to be the as-yet uncharacterized fluorescent species. On the other hand, one would not expect the spectroscopy of the van der Waals complex to be so similar to that of the monofluoride, as is observed for the new krypton-containing species. ${ }^{15}$ It is possible that in the environment of a low-temperature matrix, the triplet may be able to avoid intersystem crossing. A more definitive test of this hypothesis requires the study of the excited states of these species. Calculations on the analogous xenon species are currently underway.

\section{ACKNOWLEDGMENTS}

G.J.H. thanks the National Partnership for Advanced Computational Infrastructure (NPACI) for its allocation of time on the Cray C90 at the San Diego Supercomputer Center. R.J.C. thanks the Camille and Henry Dreyfus Foundation for a Camille and Henry Dreyfus Teacher-Scholar award, and the National Science Foundation, for Grant No. CHE9731634

${ }^{1}$ J. J. Turner and G. C. Pimentel, Science 140, 974 (1963).

${ }^{2}$ F. Schreiner, J. G. Malm, and J. C. Hindman, J. Am. Chem. Soc. 87, 25 (1965).

${ }^{3}$ P. S. Bagus, B. Liu, and H. F. Schaefer III, J. Am. Chem. Soc. 94, 6635 (1972).

${ }^{4}$ S. Huzinaga, M. Klobukowski, and Y. Sakai, J. Phys. Chem. 88, 4880 (1984).

${ }^{5}$ P. J. MacDougall, G. J. Schrobilgen, and R. F. W. Bader, Inorg. Chem. 28, 763 (1989).

${ }^{6}$ H. Bürger, R. Kuna, S. Ma, J. Breidung, and W. Thiel, J. Chem. Phys. 101, 1 (1994).

${ }^{7}$ B. Liu and H. F. Schaefer III, J. Chem. Phys. 55, 2369 (1971)

${ }^{8}$ D. H. Liskow, H. F. Schaefer III, P. S. Bagus, and B. Liu, J. Am. Chem. Soc. 95, 4056 (1973).

${ }^{9}$ P. J. Hay and T. H. Dunning, Jr., J. Chem. Phys. 66, 1306 (1977).

${ }^{10}$ T. H. Dunning, Jr. and P. J. Hay, J. Chem. Phys. 69, 134 (1978).

${ }^{11}$ P. J. Hay and T. H. Dunning, Jr., J. Chem. Phys. 69, 2209 (1978).

${ }^{12}$ C. H. Becker, P. Casavecchia, and Y. T. Lee, J. Chem. Phys. 70, 2986 (1979).

${ }^{13}$ V. Aquilanti, E. Luzzatti, F. Pirani, and G. G. Volpi, J. Chem. Phys. 89, 6165 (1988)
${ }^{14}$ D. Schröder, J. N. Harvey, M. Aschi, and H. Schwarz, J. Chem. Phys. 108, 8446 (1998).

${ }^{15}$ C. Bresler, W. G. Lawrence, and N. Schwentner, J. Chem. Phys. 105, 10178 (1996).

${ }^{16}$ J. Goodman and L. E. Brus, J. Chem. Phys. 65, 3808 (1976).

${ }^{17}$ G. Zerza, G. Sliwinski, N. Schwentner, G. J. Hoffman, D. G. Imre, and V. A. Apkarian, J. Chem. Phys. 99, 8414 (1993).

${ }^{18}$ G. J. Hoffman, D. G. Imre, R. Zadoyan, N. Schwentner, and V. A. Apkarian, J. Chem. Phys. 98, 9233 (1993).

${ }^{19}$ N. Schwentner and V. A. Apkarian, Chem. Phys. Lett. 154, 413 (1989).

${ }^{20}$ D. Cappelletti, F. Pirani, and V. Aquilanti, private communication. This potential appeared previously in reference 30 .

${ }^{21}$ GAUSSIAN 94 (Revisions B.1-E.1) M. J. Frisch, G. W. Trucks, H. B. Schlegel, P. M. W. Gill, B. G. Johnson, M. A. Robb, J. R. Cheeseman, T. A. Keith, G. A. Petersson, J. A. Montgomery, K. Raghavachari, M. A. AlLaham, V. G. Zakrzewski, J. V. Ortiz, J. B. Foresman, J. Cioslowski, B. B. Stefanov, A. Nanayakkara, M. Challacombe, C. Y. Peng, P. Y. Ayala, W. Chen, M. W. Wong, J. L. Andres, E. S. Replogle, R. Gomperts, R. L. Martin, D. J. Fox, J. S. Binkley, D. J. Defrees, J. Baker, J. P. Stewart, M. Head-Gordon, C. Gonzalez, and J. A. Pople, Gaussian, Inc., Pittsburgh, PA, 1995.

${ }^{22}$ A. Schafer, C. Huber, and R. Ahlrichs, J. Chem. Phys. 100, 5829 (1994).

${ }^{23}$ Basis sets were obtained from the Extensible Computational Chemistry Environment Basis Set Database, Version 1.0, as developed and distributed by the Molecular Science Computing Facility, Environmental and Molecular Sciences Laboratory which is part of the Pacific Northwest Laboratory, P.O. Box 999, Richland, Washington 99352, U.S.A., and funded by the U.S. Department of Energy. The Pacific Northwest Laboratory is a multiprogram laboratory operated by Battelle Memorial Institute for the U.S. Department of Energy under contract DE-AC06-76RLO 1830. Contact David Feller, Karen Schuchardt, or Don Jones for further information.

${ }^{24}$ M. M. Hurley, L. F. Pacios, P. A. Christiansen, R. B. Ross, and W. C. Ermler, J. Chem. Phys. 84, 6840 (1986).

${ }^{25}$ Gaussian Basis Sets for Molecular Calculations, edited by S. Huzinaga (Elsevier, Amsterdam, 1984).

${ }^{26}$ P. O. Widmark, P. A. Malmqvist, and B. Roos, Theor. Chim. Acta 77, 291 (1990).

${ }^{27}$ J. Cizek, Adv. Chem. Phys. 14, 35 (1969); G. D. Purvis and R. J. Bartlett, J. Chem. Phys. 76, 1910 (1982); G. E. Scuseria, C. L. Hansen, and H. F. Schaefer III, ibid. 89, 7382 (1988); G. E. Scuseria and H. F. Schaefer III, ibid. 90, 3700 (1989); J. A. Pople, M. Head-Gordon, and K. Raghavachari, ibid. 87, 5968 (1987).

${ }^{28}$ S. F. Boys and F. Bernardi, Mol. Phys. 19, 553 (1970).

${ }^{29}$ S. Huzinaga, Comput. Phys. Rep. 2, 279 (1985).

${ }^{30}$ G. Lo and D. W. Setser, J. Chem. Phys. 100, 5432 (1994).

${ }^{31}$ C. E. Moore, Atomic Energy Levels, Natl. Bur. Stand. Circ. 467, 1 (1949); 2 (1952); 3 (1958).

${ }^{32} \mathrm{P}$. J. Hay, private communication.

${ }^{33}$ J. Berkowitz and W. A. Chupka, Chem. Phys. Lett. 7, 447 (1970).

${ }^{34}$ N. Bartlett and F. O. Sladsky, "The Chemistry of Krypton, Xenon and Radon," in Comprehensive Inorganic Chemistry, edited by A. F. Trotman-Dickensen (Permagon, Oxford, 1973), Vol. 1, pp. 213-330.

${ }^{35}$ Note that the sequential removal of F-atoms from this molecule will yield different bond energies for each $\mathrm{F}$, neither of which is equal to the number given here.

${ }^{36}$ C. A. Coulson, J. Chem. Soc. 1442 (1964).

${ }^{37}$ K. P. Huber and G. Herzberg, Constants of Diatomic Molecules (Van Nostrand Reinhold, New York, 1979). 